\title{
DISCUTINDO AS RESTRIÇÕES DE MARCAÇÃO POSICIONAL: UMA PROPOSTA DE FORMALIZAÇÃO DA DIFERENÇA DE PONTO DE ARTICULAÇÃO EM CODA ${ }^{1}$
}

Ubiratã Kickhöfel ALVES

Universidade Federal do Rio Grande do Sul (UFRGS)

\section{RESUMO}

Neste trabalho, apresentamos uma proposta de formalização da oposição a ponto de articulação em coda, através de restrições conjuntas de caráter estringente. Argumentaremos que a formação de restrições conjuntas se mostra mais apropriada tanto em termos de economia descritiva como de adequação formal.

\section{ABSTRACT}

In this article, we present a proposal of Stringent Conjoined Constraints to account for positional markedness in codas. We aim to show that our proposal proves to be beneficial not only in terms of economy, but also as we consider the issue of formal adequacy.

\section{PALAVRAS-CHAVE}

Aquisição de L2. Marcação posicional. Ponto de articulação. Relações de estringência. Restriçoes conjuntas.

\section{KEY-WORDS}

Conjoined constraints. L2 acquisition.positional. Markedness. Place of articulation. Stringency relations.

\footnotetext{
${ }^{1}$ Agradeço a Profa. Dra. Leda Bisol (PUCRS), pela orientação da Tese de Doutorado da qual se originou o presente trabalho, e o Prof. Dr. Rubens Lucena (UFPB), pelos comentários referentes à sua leitura do manuscrito deste texto. Quaisquer inadequações que possa haver são de minha inteira responsabilidade.
}

(C) Revista da ABRALIN, v.10, n.1, p. 113-146, jan./jun. 2011 
Discutindo as Restriçốes de Marcaçấo Posicional: uma Proposta de Formalizaçāo da Diferença de Ponto de Articulaçáo em Coda

\section{Introdução}

Na Teoria da Otimidade (PRINCE \& SMOLENSKY, 1993/2004), a gramática de uma língua é determinada pelo ranking de restrições. No estágio atual em que se encontra tal modelo teórico, uma dificuldade a ser enfrentada pelo analista diz respeito à escolha da restrição de marcação a ser adotada. Com o grande número de trabalhos de análise já desenvolvidos, encontramos, na literatura, uma variedade considerável de restrições que, apesar de exercerem o mesmo papel em termos de marcas de violação, apresentam diferentes descrições estruturais e, até mesmo, diferentes nomes e definições.

As restrições de marcação posicional caracterizam um excelente exemplo do acima afirmado. Ao tentarmos formalizar a proibição a um determinado ponto de articulação em coda, podemos encontrar uma grande gama de restrições capazes de exercer tal papel. Como exemplo, encontramos restrições que concebem a oposição a ponto como um conjunto de restrições sob o rótulo CodaCond (LOMBARDI, 2001), ou, ainda, através da atribuição direta do ponto em si à posição de coda, tal como em $* \mathrm{NoCoda}_{\text {(dorsal) }}$ ou em $*\{\text { labial }\}_{\text {coda }}$. Encontramos, ainda, a oposição a ponto em coda através da conjunção de restrições de caráter não-estringente, tal como [Labial \& NoCoda] (ITÔ \& MESTER, 1998; ZOLL, 1998). Fica clara, assim, a grande quantidade de distintas formalizações de restrições encontradas no modelo, com o intuito de realizar um único papel, em termos de oposição.

O presente trabalho apresenta uma nova possibilidade de formalização de marcação referente à posição de coda: a proposta de formação de restrições conjuntas de caráter estringente, capazes de diferenciar segmentos de mesma sonoridade, porém com pontos de articulação distintos. Para exemplificarmos os mecanismos formais que caracterizam a proposta, o trabalho se desenvolverá a partir da discussão da diferença entre plosivas coronais, labiais e dorsais em coda. Argumentos que justifiquem a necessidade de distinção entre esses três 
pontos de articulação, dentro da classe de plosivas, serão fornecidos a partir de dados de aquisição do inglês por brasileiros. Demonstraremos que a proposta aqui apresentada se revela adequada tanto em termos de economia de análise quanto no que concerne à adequação dos mecanismos de formalização empregados.

\section{A formalização da oposição a $/ \mathrm{p} /, / \mathrm{t} / \mathrm{e} / \mathrm{k} /$}

\subsection{A necessidade de distinguir /p/, /t/ e / k/: os dados}

Ao considerarmos a oposição aos segmentos plosivos em coda, o primeiro questionamento a ser feito diz respeito à efetiva necessidade de formalização de restrições distintas, que façam menção individual a cada um dos pontos de articulação. De fato, em função da necessidade de uma análise mais econômica, poderíamos questionar se uma restrição única tal como $*\{\text { stop }\}_{(\text {coda) }}$, que faça referência à classe de plosivas como um todo, não se mostraria igualmente eficaz para dar conta dos dados linguísticos, de modo a garantir, dessa forma, uma análise mais econômica.

A resposta para a indagação acima só poderá ser fornecida a partir dos dados linguísticos. Nesse sentido, os dados de aquisição do inglês por falantes do português brasileiro caracterizam-se como uma fonte de material empírico rica para que cheguemos a essa posição teórica. Em nossa língua, /p/, /t/ e /k/ são proibidos em coda, sendo a epêntese o processo utilizado quando os aprendizes se deparam com exemplares de input da L2 finalizados por segmentos plosivos. Assim, caso não encontremos diferenças nas trajetórias de aquisição de /p/, /t/ e /k/, podemos dizer que não há necessidade de diferenciar, em termos de restrições, esses três segmentos: $*\{\text { stop }\}_{\text {coda }}$ estaria desempenhando o papel de representar a aquisição de toda a classe de plosivas, de modo que se obtenha um menor número de restrições, em nossa análise. Por outro lado, caso a observação dos dados revele graus de dificuldade distintos 
Discutindo as Restriçốes de Marcaçấo Posicional: uma Proposta de Formalizaçāo da Diferença de Ponto de Articulaçấo em Coda

para a aquisição de cada um dos segmentos, fica clara a necessidade de uma distinção em função do ponto de articulação da plosiva. Garantiremos, assim, uma análise capaz de refletir mais adequadamente o que ocorre na língua do aprendiz.

Para a verificação da necessidade de distinção entre /p/, /t/ e /k/ em coda, devemos nos voltar para a literatura acerca da aquisição silábica do inglês por brasileiros. Faremos menção, nesse sentido, aos estudos de Koerich (2002), Silveira (2004, 2007), Cardoso (2005) e Alves (2008). Os dados apresentados em todos esses estudos confirmam que a aquisição da plosiva dorsal em coda se mostra mais dificultosa do que a aquisição das plosivas labial e coronal, e sugerem, também, que a plosiva coronal é a primeira a ser adquirida. Fica clara, assim, a necessidade de análises distintas para o processo de aquisição de cada um dos segmentos plosivos em coda, uma vez que as trajetórias desenvolvimentais, conforme apontam os dados apresentados nos estudos mencionados, se mostram distintas.

Atenção especial deve ser dada aos estudos de Cardoso (2005) e Alves (2008), estudos esses desenvolvidos à luz da Teoria da Otimidade. Cardoso (2005), ao investigar a produção de palavras mono e polissilábicas do inglês por parte de seis aprendizes divididos em três níveis de proficiência (básico, intermediário e avançado), demonstra haver uma diferença estatística significativa referente à variável 'ponto de articulação', visto que as palavras finalizadas por plosivas coronais foram produzidas com menores índices de epêntese nos três níveis de proficiência. As dorsais, por sua vez, mostraram-se as mais dificultosas para os aprendizes, independentemente do nível de adiantamento na língua. Como ilustração, podemos citar os resultados de produção de plosivas finais no nível intermediário, em que foram produzidas 43\% de /t/ final, 19\% de /p/ final e apenas 14\% de palavras encerradas pela plosiva dorsal, o que comprova o caráter mais marcado do ponto dorsal e o menos marcado das plosivas coronais finais. 
Argumentos adicionais favoráveis ao emprego de restrições distintas em função do ponto de articulação mostram-se disponíveis a partir da verificação dos dados de Alves (2008). O autor investigou a produção de palavras monossilábicas encerradas pelas plosivas /p/, / t/ e k/, por parte de 32 sujeitos em 4 níveis distintos de adiantamento (elementar, intermediário, intermediário-superior e proficiente). Os dados demonstraram ocorrências de epêntese apenas no nível mais básico de proficiência, e apenas após o segmento dorsal (4,88\% em 6 de 123 ocorrências). Todas as $116(100 \%)$ produções de palavras encerradas por / t/ final foram realizadas sem epêntese, bem como as $122(100 \%)$ de palavras encerradas pelo segmento labial. A observação de tal padrão de produção sugere que os segmentos dorsais parecem ser, efetivamente, os últimos a serem adquiridos em posição final pelos aprendizes.

Frente a esses dados, concluímos que assumir a oposição a segmentos plosivos unicamente através da restrição $*\{\text { stop }\}_{\text {coda }}$ implica obscurecer uma importante generalização: a de que os segmentos plosivos dorsais são os últimos a serem adquiridos em coda. Em outras palavras, sem restrições específicas referentes ao ponto de articulação, não podemos formalizar o fato de que plosivas coronais, por exemplo, já se mostram plenamente adquiridas pelos aprendizes, ao passo que as dorsais ainda são produzidas com a variação [forma alvo] [epêntese], o que é o caso de 3 dos 32 sujeitos do corpus de Alves (2008).

Em suma, os dados acima discutidos confirmam a necessidade de restrições diferenciadas em função do ponto de articulação do segmento plosivo a ser adquirido em posição final, ainda que isso implique um número maior de restrições em nossa análise. De fato, a aquisição das plosivas em coda se mostra de acordo com a escala de harmonia $\mid$ dorsais $>$ labiais $>$ coronais | (PRINCE \& SMOLENSKY, 1993/2004), de acordo com a qual os segmentos dorsais, os mais marcados, caracterizam-se como justamente os de aquisição mais tardia. Evidenciada essa necessidade, é preciso buscar, na literatura, restrições 
Discutindo as Restriçốes de Marcaçấo Posicional: uma Proposta de Formalizaçāo da Diferença de Ponto de Articulaçấo em Coda

que desempenhem esse papel. Conforme já mencionamos, grande é a possibilidade de formalização de restrições capazes de desempenhar tal tarefa. No que segue, discutiremos algumas dessas possíveis restrições, discutindo as suas limitações para que possamos justificar nossa proposta de formalização.

\subsection{A oposição a /p/, /t/ e k/: critérios para a formalização}

Justificada a pertinência de formalizações distintas para cada um dos segmentos plosivos /p/, /t/ e / k/ em coda, discutiremos, nessa seção, critérios importantes de serem seguidos pelas restrições referentes a ponto de articulação em coda. Para isso, argumentaremos que a formalização de tais restrições deve obedecer, sobretudo, a duas premissas: economia e adequação formal.

Ao atendermos à premissa de adequação formal, um desafio está em como expressar, em termos de hierarquias de restrições, escalas linguísticas naturais, tais como a de sonoridade. Não menos importante do que saber "transformar" escalas naturais em rankings de restrições é determinar quais escalas de harmonia podem, e quais não podem, ser convertidas em hierarquias que se refiram a uma dada estrutura prosódica, tal como a posição de coda silábica. De fato, desde Prince \& Smolensky (1993/2004), fazemos uso de rankings de restrições diferentes para as posições de onset e coda, de modo que a hierarquia de coda privilegie segmentos com valores mais altos na escala de sonoridade, e a de onset, por sua vez, prefira o contrário. Entretanto, devemos nos perguntar se todas as escalas de harmonia podem ser formalizadas em termos de restrições de marcação posicional.

Em resposta ao questionamento feito acima, a proposta de formalização de restrições lançada por De Lacy $(2002$, 2006) mostrase importante por seu caráter de restringir a marcação posicional. Ao propor a "Restrição de Combinação entre Hierarquia e Estrutura" (Hierarchy-Structure Combination Restriction), o autor limita quais escalas 
harmônicas podem ser associadas, através de restrições de marcação, a elementos prosódicos. Transcrevemos, abaixo, as palavras do autor ao formular a restrição em questão.

(06) A restrição de Combinação entre Hierarquia e Estrutura (De Lacy, 2006, p. 69)

(a) Hierarquias que se referem a propriedades prosódicas (ex. tom, sonoridade) sempre se combinam com elementos prosódicos em restrições.

(b) Hierarquias que se referem a propriedades sub-segmentais (ex. traço, ponto de articulação) nunca se combinam com elementos prosódicos nas restrições.

A proposta lançada por De Lacy limita consideravelmente o número de restrições de marcação referentes à posição de coda, por estipular quais escalas podem ser associadas a elementos prosódicos. De acordo com o expresso em (06), a escala de sonoridade, por exemplo, pode ser "convertida", através do Alinhamento Harmônico ${ }^{2}$, em uma hierarquia de restrições para onset (em que uma restrição que se opõe a plosivas, por exemplo, é a menos marcada no ranking) e em outra hierarquia inversa, referente a codas (em que uma restrição que milita contra plosivas é a que assume o caráter mais marcado). Por outro lado, uma escala de ponto de articulação tal como $\mid$ Dorsal $>$ Labial $>$ Coronal $\left.\right|^{3}$ não pode ser formalizada em termos de marcação posicional, uma vez que ponto de articulação é uma unidade subsegmental. Uma hierarquia obtida dessa escala, nesse sentido, não pode fazer referência nem à posição de onset, nem à de coda. Restrições que estabeleçam uma condição de coda

\footnotetext{
${ }^{2}$ Maiores detalhes acerca do processo de Alinhamento Harmônico serão fornecidos na seção que segue.

${ }^{3}$ De Lacy $(2002,2006)$ inclui o ponto glotal como o menos marcado da sua hierarquia de ponto de articulação. Em nossa análise, uma vez que não estamos tratando de segmentos que contenham o ponto glotal, consideraremos, como escala de harmonia de ponto de articulação, a relação Dorsal > Labial > Coronal.
} 
Discutindo as Restriçốes de Marcaçấo Posicional: uma Proposta de Formalizaçāo da Diferença de Ponto de Articulaçấo em Coda

contra um dado ponto de articulação não são, portanto, concebidas pelo autor.

Feitas as considerações acima, podemos passar à discussão acerca do caráter econômico que deve ser apresentado pelas restrições de marcação posicional. Ao considerarmos uma língua como o português brasileiro, em que todos os segmentos plosivos são proibidos independentemente do ponto de articulação, restrições distintas para cada um desses pontos podem semostrar, apriori, como evidência de uma sobrecarga desnecessária para o componente CON. De fato, em nossa língua, tanto a restrição $*\{\text { stop }\}_{\text {coda }}$ como todas as outras restrições que se oporiam a plosivas de um ponto de articulação específico em coda teriam o mesmo status hierárquico, de modo que tais restrições referentes a ponto apresentariam caráter redundante frente à restrição geral que se opõe a toda a classe de plosivas em posição final de sílaba. Além disso, se concebermos as restrições referentes a ponto como de caráter estringente, é necessária uma formalização de restrições em que a oposição a toda a classe de segmentos, tal como $*\{\text { stop }\}_{\text {coda }}$, não apresente exatamente as mesmas marcas de violação de uma restrição referente ao ponto menos marcado, como uma oposição a plosivas coronais em coda, por exemplo. Isso se mostra bastante importante em termos de economia formal de análise, pois, se concebermos a restrição contra coronais em coda como a de caráter mais geral na relação de estringência com as oposições a plosivas labiais e dorsais, as marcas de violação incorridas por tal restrição mais geral serão exatamente as mesmas apresentadas pela oposição à classe de plosivas como um todo. Fica clara, nesse sentido, a necessidade de uma proposta de formalização em que $*\{\text { stop }\}_{\text {coda }}$ apresente um caráter mais geral, não-redundante, ao das restrições que se refiram a plosivas com pontos de articulação específicos.

As restrições que propomos em nossa análise têm por objetivo atender a essas premissas, de modo a garantir os pré-requisitos de adequação formal e economia. $\mathrm{Na}$ seção que segue, apresentamos a proposta de formalização que tem por base tais critérios. 


\subsection{A proposta: restrições conjuntas de caráter estringente}

Precisamos formalizar o fato de que, no português brasileiro, a proibição a segmentos plosivos pode ser expressa através de uma hierarquia de restrições com base na escala de sonoridade. Nesse sentido, o sistema de coda da L1 pode ser formalizado em restrições por meio de uma hierarquia de marcação advinda do processo de Alinhamento Harmônico (cf. PRINCE \& SMOLENSKY, 1993/2004), fazendose uso de restrições em relação de estringência. Partimos da escala de sonoridade expressa em (01):

(01) $\mid$ Vogais $>$ Semivogais $>$ Líquidas $>$ Nasais $>$ Fricativas $>$ Plosivas |

A partir da escala expressa em (01), e do processo de Alinhamento Harmônico dessa escala com a posição prosódica de coda silábica, podemos obter as seguintes restrições que se encontram em relação de estringência, apresentadas em (02).

$(02) \quad * \quad\{\text { stop }\}_{\text {coda }} *\{\text { stop, fric }\}_{\text {coda }}, * \quad\{\text { stop, fric,nas }\}_{\text {coda }}$,
$*\{\text { stop,fric,nas, liq }\}_{\text {coda }}$

De acordo com McCarthy (2008), as restrições obtidas através do Alinhamento Harmônico podem ser formalizadas através de duas maneiras: por meio de uma hierarquia universalmente fixa (semelhante à proposta no texto fundador da OT), ou através da geração de um conjunto de restrições que se encontram em uma relação de estringência. Optamos, em nossa análise, pela formalização de restrições de caráter estringente, pois, conforme evidencia McCarthy (op. cit.), essas são capazes de dar conta de todos os processos analisáveis através de um ranking fixo, além de conseguirem, também, explicar ranqueamentos do tipo anti-panini (geral dominando o específico), o que não é possível através de restrições que apresentam um ranking fixo. 
Discutindo as Restriçốes de Marcaçấo Posicional: uma Proposta de Formalizaçāo da Diferença de Ponto de Articulaçấo em Coda

A noção de estringência foi primeiramente apresentada por Prince (1997 a, b), e vem sendo utilizada em diversos trabalhos da área, assumindo papel de destaque na Teoria de Marcação proposta por De Lacy $(2002$, 2006). Em uma relação de estringência entre A e B , a restrição A é mais estringente do que a restrição $B$ se toda a violação de B for, também, uma violação de $A$, ainda que haja algumas violações de A que não sejam violações de B. Em outras palavras, as violações de $\mathrm{B}$ correspondem a um subconjunto das violações de $\mathrm{A}$. Restrições que se encontram em relação de estringência, dessa forma, não precisam apresentar uma relação de dominância fixa. Considerando-se o ranking em (2), a violação da restrição que se opõe a um segmento plosivo, através da relação de estringência, implica a violação de todas as outras restrições de caráter mais geral. Em termos de aquisição, isso significa que um input com um segmento plosivo ocasiona a demoção de todas as restrições da hierarquia. Já um input que contenha uma líquida final, por exemplo, implica a demoção apenas da restrição de caráter mais geral.

No português brasileiro, uma vez que nenhuma plosiva é permitida em coda, $*\{\text { stop }\}_{\text {coda }}>>$ DEP. Adquirir as plosivas finais significa, portanto, atingir um ranqueamento caracterizado por uma posição inferior não somente de $*\{\text { stop }\}_{\text {coda }}$, mas também das outras restrições que aqui proporemos, restrições essas referentes a plosivas com ponto de articulação específicos. De fato, como vimos nos dados discutidos na seção $2.1, *\{\text { stop }\}_{\text {coda }}$ não se faz suficiente para distinguir os diferentes tipos de segmentos plosivos. É preciso, portanto, considerarmos a escala harmônica referente a ponto de articulação, apresentada em (03), da qual resultam as relações de estringência apresentadas em (04).
(03) $\mid$ dorsal $>$ labial $\rangle$ coronal $\mid$
(04) $*\{$ dorsal $\}, *\{$ dorsal,labial $\}, *\{$ dorsal,labial,coronal $\}$ 
A partir das relações de estringência previstas em (04), De Lacy (2006: 72) prevê a possibilidade de existência de restrições de marcação referentes a ponto específicas a um modo de articulação (manner-specific $P O A$ constraints). Ao assumirmos tal possibilidade, podemos conceber uma escala referente a ponto com menção específica a um dado modo de articulação, como vemos em (05), através da qual é expresso o fato de que /t/ é o segmento menos marcado, e /k/, o mais marcado.

(05) $*\{$ dors $\} /$ stop, $*\{$ dors,lab $\} /$ stop, $*\{$ dors,lab,cor $\} /$ stop

Precisamos, então, atribuir as oposições em (05) à coda silábica. Conforme já discutimos na seção anterior, ao considerarmos uma relação de estringência entre os pontos de articulação, a restrição referente a ponto de caráter mais geral não pode assumir um caráter redundante ao de $*\{\text { stop }\}_{\text {coda }}$, ao assumirmos a premissa de uma formalização econômica de restrições. Vemos, assim, que não há necessidade de uma restrição que faça referência específica ao ponto coronal, o menos marcado ${ }^{4}$ a própria restrição advinda do alinhamento harmônico, $*\{\text { stop }\}_{\text {codal }}$, desempenha esse papel. São necessárias, entretanto, restrições que distingam as plosivas coronais labiais e coronais, em posição final. Para formalizar tais oposições, propomos que as diferenças entre pontos de articulação sejam expressas através da conjunção de duas restrições: uma que diga respeito à sonoridade dos elementos em coda, advinda das relações estringentes apresentadas em (02), e outra que diga respeito ao ponto de articulação, advinda de (05). Dessa forma, para diferenciarmos codas de plosivas coronais das que exibem labiais e dorsais, propomos a restrição conjunta expressa em (06):

$$
\text { (06) }\left[*\{\text { stop }\}_{\text {coda }} \& *\{\text { dors,lab }\} / \text { stop }\right]_{(\text {coda })}
$$

\footnotetext{
${ }^{4} \mathrm{Na}$ seção que segue, veremos que o mecanismo de Conjunção Local dá conta da inexistência de tal restrição, pelo fato de operar sob a premissa de não-formação de restrições conjuntas que exerceriam caráter redundante.
} 
Discutindo as Restriçốes de Marcaçấo Posicional: uma Proposta de Formalizaçāo da Diferença de Ponto de Articulaçấo em Coda

A partir da restrição apresentada acima, vemos que a produção do segmento /p/ em coda implica, portanto, mais do que a dominância de DEP sobre $*\{\text { stop }\}_{\text {coda }}$ É preciso, também, que $\left[*\{\text { stop }\}_{\text {coda }} \&\right.$ $*\{$ dors,lab $\} /$ stop $]_{\text {(coda) }}$ esteja menos ranqueada do que DEP.

A formulação de restrições que estamos aqui propondo prevê, portanto, a possibilidade de estágios hierárquicos em que /t/ já foi adquirido na posição de coda, sem mais haver epêntese nas sílabas fechadas por tal segmento, ao contrário de palavras encerradas por $/ \mathrm{p} /$. Ao considerarmos o processo de aquisição sob a premissa teórica do Algoritmo de Aprendizagem Gradual (BOERSMA \& HAYES: 2001), isso significa dizer que $*\{\text { stop }\}_{\text {coda }}$ já apresenta um valor central afastado e inferior ao de DEP (ou seja, sem mais cruzamento entre as faixas de valores), ao passo que o valor central de $\left[*\{\text { stop }\}_{\text {coda }} \& *\{\right.$ dors,lab $\left.\} /{ }_{\text {stop }}\right]$ (coda) ainda se apresenta bastante próximo (no caso da variação $[\mathrm{p}] \sim[\mathrm{pi}]$ ), ou, então, consideravelmente superior (no caso em que a epêntese é produzida categoricamente) ao da restrição de fidelidade.

A restrição conjunta $\left[*\{\text { stop }\}_{\text {coda }} \& *\{\text { dors,lab }\} / \text { stop }\right]_{(\text {coda })}$ expressa, em termos de marcação, a diferença entre plosivas coronais e os demais pontos. Não diferencia, entretanto, casos de produção de [p] e [k] finais. Uma vez que os dados de Alves (2008) apontaram manifestações de epêntese após palavras da L2 encerradas pelo segmento dorsal, mas não após labiais, precisamos diferenciar codas preenchidas por plosivas dorsais das ocupadas por labiais. Dada essa necessidade, nossa análise recorrerá a uma outra restrição conjunta, expressa em (07).

$$
\text { (07) }\left[*\{\text { stop }\}_{\text {coda }} \& *\{\text { dors }\} / \text { stop }\right]_{(\text {coda })}
$$

Novamente, temos a conjunção entre uma restrição que se refere à escala de sonoridade, e outra restrição que milita contra o ponto de articulação mais marcado. Vale esclarecer que a restrição em (07) apresenta um caráter mais específico do que a apresentada em (06). Ambas, por 
sua vez, são mais específicas do que a restrição de sonoridade $*$ \{stop $\}$ coda. Evidenciamos, no quasi-tableau ${ }^{5}$ em (08), a relação de estringência entre as três restrições aqui propostas:

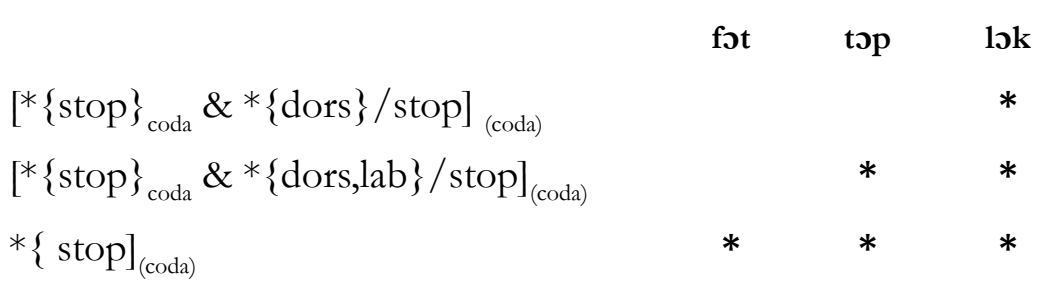

Em suma, a distinção entre /p/, / t/ e k/ em coda se dá através da ação de dois mecanismos formais, na Teoria: o Alinhamento Harmônico, que fornece a restrição que vai se opor à classe de sonoridade "plosiva" como um todo, e o mecanismo de Conjunção Local. Ao concebermos o mecanismo de Conjunção Local como formador de restrições em caráter de estringência, garantimos o fato de que plosivas labiais são menos marcadas do que dorsais. A relação entre plosivas coronais, labiais e dorsais é, portanto, preservada, não através de um ranking fixo; advém, na verdade, das próprias marcas de violação incorridas pelas restrições em relação de estringência.

Apresentada a formalização das restrições em (06) e (07), é necessário discutir de que modo essas se mostram mais econômicas e formalmente adequadas do que as restrições referentes a ponto de articulação encontradas na literatura. Além disso, maiores esclarecimentos acerca do mecanismo de conjunção " $\&$ " são necessários. Precisamos, de fato, explicar por que uma restrição tal como $\left[*\{\text { stop }\}_{\text {coda }} \& *\{\right.$ dors,lab,cor $\} /$ stop] $]_{\text {(coda) }}$ não é formada, bem como explicitar o momento em que ocorre a formação das restrições conjuntas $\left[*\{\text { stop }\}_{\text {coda }} \& *\{\right.$ dors,lab $\} /$ stop $]_{(\text {coda })}$ e $\left[*\{\text { stop }\}_{\text {coda }} \& *\{\text { dors }\} / \text { stop }\right]_{(\text {coda })}$, além de apontar critérios

\footnotetext{
${ }^{5} \mathrm{Um}$ quasi-tablean é um dispositivo formal através do qual podemos expressar as marcas de violação incorridas por possíveis formas de saída. Em um quasi-tableau, não existe concorrência entre candidatos, tampouco a escolha de um output ótimo.
} 
Discutindo as Restriçốes de Marcaçấo Posicional: uma Proposta de Formalizaçāo da Diferença de Ponto de Articulaçấo em Coda

que limitem a produção incontrolada de restrições conjuntas. Isso será feito na próxima seção.

\section{Discussão: implicações da proposta}

A presente seção tem a intenção de demonstrar as vantagens das restrições apresentadas em (06) e (07) sob os aspectos de economia e adequação formal, bem como discutir a abrangência do modelo proposto para análises outras que a aquisição do inglês por falantes brasileiros. Antes disso, é necessária uma discussão sobre a atuação do mecanismo formal de construção de restrições conjuntas e os critérios que justificam a formação de tais restrições.

\subsection{Uma discussão sobre o operador de Conjunção Local " $\&$ "}

Nesta seção, discutiremos em que momento, e por quê, se dá a formação das restrições $\left[*\{\text { stop }\}_{\text {coda }} \& *\{\text { dors,lab }\} / \text { stop }\right]_{(\text {coda })}$ e $[*\{$ stop $\}$ ${ }_{\text {coda }} \& *\{$ dors $\} /$ stop $]_{(\text {coda) }}$, apresentadas na seção anterior. Nesse sentido, um questionamento bastante pertinente diz respeito a se tais restrições já se mostravam presentes antes mesmo do início do processo de aquisição de L2.

Para respondermos a essa questão, seguiremos a premissa de que, para haver a conjunção, ambas as restrições que compõem a restrição conjunta já devem apresentar um valor central mais baixo no ranking, ao considerarmos o Algoritmo de Aprendizagem Gradual, de Boersma \& Hayes (2001). Essa idéia vai ao encontro da concepção de Conjunção Local como último recurso (FUKAZAWA 1999, 2001; FUKAZAWA \& MIGLIO 1998; BONILHA 2003, 2005), uma vez que tal condição impede a formação de restrições conjuntas que estejam desempenhando um papel redundante na língua. Ao considerarmos tal premissa, concluímos que a formação das restrições $\left[*\{\text { stop }\}_{\text {coda }} \& *\{\right.$ dors,lab $\} /$ stop $]_{(\text {coda })}$ e $\left[*\{\text { stop }\}_{\text {coda }} \& *\{\text { dors }\} / \text { stop }\right]_{(\text {coda })}$ se dá apenas no processo de 
aquisição de L2. Na L1 dos aprendizes, $*\{\text { stop }\}_{\text {coda }}$ caracteriza a oposição aos três segmentos plosivos em coda, sem serem necessárias restrições que diferenciem as plosivas finais em termos de ponto de articulação: há epêntese vocálica após esses três segmentos.

Em outras palavras, a justificativa para negarmos a possibilidade de formação das restrições $\left[*\{\text { stop }\}_{\text {coda }} \& *\{\text { dors,lab }\} / \text { stop }\right]_{(\text {coda })}$ e $[*\{$ stop $\}$ ${ }_{\text {coda }} \& *\{$ dors $\} /$ stop $]_{\text {(coda) }}$ no português brasileiro advém das limitações que propusemos ao mecanismo de Conjunção Local. Nesse sentido, é importante que deixemos claro um dos pontos cruciais de nossa análise: a prerrogativa de que restrições conjuntas só podem ser formadas se apresentarem um caráter não-redundante. Como, no português brasileiro, tanto $[\mathrm{t}]$ como $[\mathrm{p}]$ e $[\mathrm{k}]$ são proibidos em coda (uma vez que $*\{\text { stop }\}_{\text {coda }}$ apresenta um valor bastante superior ao de DEP), as restrições conjuntas em questão não desempenhariam valor decisivo no ranking, o que faz com que uma possível conjunção de restrições assuma caráter redundante, em nossa língua.

Estamos considerando, portanto, que o mecanismo de Conjunção Local se mostra ativo no processo de aquisição de L2. Enquanto não há evidência positiva com uma plosiva em posição final, * $\{\text { stop }\}_{\text {coda }}$ não é demovida; por conseguinte, não pode haver a formação das conjuntas, uma vez que essas ainda assumem caráter redundante. Com o início da demoção de tal restrição, a partir da evidência positiva da L2 com plosivas em posição final, o aprendiz sente a necessidade, portanto, de diferenciar os segmentos plosivos, em termos de ponto de articulação. A formação de uma restrição conjunta que se oponha ao segmento labial só se fará possível após o aprendiz ter recebido evidência positiva com a plosiva coronal. Se isso não ocorrer, a restrição $*\{\text { stop }\}_{\text {coda }}$, que constitui um dos membros da restrição conjunta a ser formada, não estará apresentando um valor central mais baixo do que o da possível conjunta, o que impede a sua formação. A partir da presença de / $\mathrm{t} /$ na evidência positiva, $\mathrm{o}$ valor central de $*\{\text { stop }\}_{\text {coda }}$ começa a diminuir, de acordo com o algoritmo de 
Discutindo as Restriçốes de Marcaçấo Posicional: uma Proposta de Formalizaçāo da Diferença de Ponto de Articulaçấo em Coda

Boersma \& Hayes (2001), e a nova restrição conjunta pode ser formada.

Uma vez que o input da L2 conta, também, com plosivas labiais, uma restrição conjunta que se oponha especificamente à plosiva dorsal também deverá ser formada, o que distinguirá, em termos de marcação, a aquisição de /p/ e / k/ finais. Conforme vimos, a relação de estringência

entre $\left[*\{\text { stop }\}_{\text {coda }} \& *\{\text { dors,lab }\} / \text { stop }\right]_{\text {(coda) }}$ e $\left[*\{\text { stop }\}_{\text {coda }} \& *\{\right.$ dors $\} /$ stop $]_{(\text {coda) }}$ prevê a aquisição das codas que exibem [p] anteriormente à das que contêm $[\mathrm{k}]$.

Precisamos salientar, ainda, que uma restrição conjunta que se refira aos três pontos de articulação, tal como $\left[*\{\text { stop }\}_{\text {coda }} \& *\{\right.$ dors,lab,cor $\} /$ stop] $]_{(\text {coda) }}$, nunca poderá ser formada. De fato, tal restrição estaria desempenhando o mesmo papel de $*\{\text { stop }\}_{\text {coda }}$ o que confere a ela, portanto, caráter redundante, proibido pelo mecanismo de Conjunção Local.

Nossa análise prevê, conforme já dissemos, a formação de restrições conjuntas somente quando a restrição que se mostra mais geral, em um par estringente com a restrição conjunta que pode vir a ser formada, apresentar-se mais baixa, em termos de ranking, do que o que seria assumido pela nova conjunta. Isso é possível se, no processo de aquisição de linguagem, houver evidência positiva com a presença de um ponto de articulação menos marcado do que aquele(s) ao(s) qual(ais) a possível conjunta faz menção. Garantimos, através da união entre o mecanismo de Conjunção Local e a noção de estringência, uma análise mais econômica, a partir de restrições referentes a ponto que desempenharão efetivo papel ao longo do processo de aquisição.

\subsection{A pertinência da proposta frente a outras possibilidades de formalização}

A proposta que aqui apresentamos é desenvolvida a partir de duas premissas centrais: economia e adequação formal. Ao considerarmos individualmente essas duas premissas, discutiremos o desempenho das 
restrições conjuntas que aqui sugerimos frente a outras possibilidades de formalização de restrições de marcação, encontradas nas análises em OT.

Comecemos nossa discussão retomando a noção de economia, já abordada na seção anterior. A proposta de restrições conjuntas estringentes se mostra econômica em função dos pressupostos obedecidos pelo próprio mecanismo de formação de restrições. Em primeiro lugar, ressaltemos que as restrições $\left[*\{\text { stop }\}_{\text {coda }} \& *\{\right.$ dors,lab $\} /$ stop $]_{(\text {coda })}$ e $\left[*\{\text { stop }\}_{\text {coda }} \& *\{\text { dors }\} / \text { stop }\right]_{(\text {coda })}$ só são formadas na própria aquisição da segunda língua; no português brasileiro, a formação de tais restrições não se mostra possível, pois tais conjuntas assumiriam caráter redundante frente $a *\{\text { stop }\}_{\text {coda }}$. De fato, a formação da restrição conjunta só se faz possível a partir da exemplares de evidência positiva com plosivas finais, o que acarreta a demoção de $*\{\text { stop }\}_{\text {coda }}$, uma das componentes da restrição conjunta a ser formada. Tal característica se mostra como uma solução mais econômica frente a restrições do tipo *p, [*\{labial $\} /$ stop $]_{\text {coda }}$ ou *(labial $)_{\text {coda }}$. Assumir tais restrições implica considerar hierarquias de restrições que, independentemente de se apresentarem sob um ranking fixo (tal como $*[\{\text { dorsal }\} / \text { stop }]_{\text {coda }}>*[\{$ labial $\} /$ stop $]$ coda $>*[\{\text { coronal }\} / \text { stop }]_{\text {coda }}$ ou sob uma relação de estringência (tal como $*[\{\text { dorsal }\} / \text { stop }]_{\text {coda }}, *[\{\text { dorsal,labial }\} / \text { stop }]_{\text {coda }} *[\{$ dorsal, labial, coronal $\} /$ stop $_{\text {coda }}$ ), devem se fazer presentes em CON desde o início do processo de aquisição da própria língua-materna, altamente ranqueadas. Temos, através dessas hierarquias, um sistema de CON mais pesado, com um número maior de restrições, cujos efeitos são os mesmos obtidos pelas restrições conjuntas por nós propostas (ressaltemos, nesse sentido, o fato de que as restrições conjuntas não se encontram armazenadas em $\left.\mathrm{CON}^{6}\right)$. De fato, somente através do mecanismo de conjunção local conseguimos estabelecer restrições que, mesmo não estando presentes

\footnotetext{
${ }^{6} \mathrm{O}$ uso de restrições conjuntas na aquisição de linguagem foi primeiramente proposto em Bonilha (2003), que argumenta que universal é o mecanismo de Conjunção Local, não as restrições conjuntas. $O$ presente trabalho parte de tal consideração, acrescentando a noção de estringência às restrições conjuntas.
} 
Discutindo as Restriçốes de Marcaçấo Posicional: uma Proposta de Formalizaçāo da Diferença de Ponto de Articulaçấo em Coda

na GU, possam vir a ter seus efeitos sentidos no momento de aquisição em que seus efeitos se fazem necessários.

Ainda com relação ao caráter econômico da proposta, ressaltemos a premissa de formação de restrições de estringência de caráter nãoredundante, o que impede a formação de uma restrição $\left[*\{\text { stop }\}_{\text {coda }} \&\right.$ $*\{$ dors,lab,cor $\} /$ stop $]_{(\text {coda })}$, conforme já explicitamos. A distinção entre $/ \mathrm{t} /, / \mathrm{p} / \mathrm{e} / \mathrm{k} /$, dessa forma, se dá a partir de apenas duas restrições referentes a ponto: $\left[*\{\text { stop }\}_{\text {coda }} \& *\{\text { dors,lab }\} / \text { stop }\right]_{(\text {coda })}$ e $\left[*\{\text { stop }\}_{\text {coda }}\right.$ $\& *\{$ dors $\} /$ stop $]_{(\text {coda })}$. Propostas de formalização que não façam uso da conjunção local não conseguem se livrar do caráter redundante que possíveis restrições referentes ao ponto menos marcado, tais como $*[\{\text { dors, lab,cor }\} / \text { stop }]_{\text {(coda) }}$ (concebendo-se um ranking estringente) ou $[(\operatorname{cor}\} / \text { stop }]_{\text {(coda) }}$ (concebendo-se um ranking fixo) apresentariam frente a $*\{\text { stop }\}_{(\text {coda })}$. De fato, ao não contarmos com o mecanismo de conjunção local, precisamos conceber a existência de tais restrições hipotéticas em CON desde o início do processo de aquisição de L1.

Uma possível solução para esse caso seria deixar de conceber o mecanismo de Alinhamento Harmônico, de modo que a existência de $*\{\text { stop }\}_{\text {(coda) }}$ fosse desconsiderada (pois, conforme poderia ser argumentado, as três restrições referentes a ponto seriam capazes de exercer o seu papel). Ao desconsiderarmos a existência de restrições tais como $*\{\text { stop }\}_{\text {coda }} \mathrm{e}^{*}\{\text { stop, fric }\}_{\text {coda }}$, encontramos dificuldades para expressar a relação entre segmentos de sonoridade diferente. Frente à tarefa de expressarmos o fato que plosivas são mais marcadas do que fricativas, vemos que nem um ranking fixo, nem restrições em estringência conseguem ter sucesso, ao desconsiderarmos as restrições obtidas do Alinhamento Harmônico. 
Sob a noção de um ranking fixo, poderíamos sugerir algo como $*\left[\{\right.$ dorsal $\} /$ stop $_{\text {coda }}{ }^{7}>>*[\{\text { labial }\} / \text { stop }]_{\text {coda }}>>*[\{\text { coronal }\} / \text { stop }]_{\text {coda }}$ $>>*[\{\text { dorsal }\} / \text { fricative }]_{\mathrm{coda}}>>*[\{\text { labial }\} / \text { fricative }]_{\mathrm{coda}}>>*[\{$ coronal $\} /$ fricative $_{\text {coda }}$. Tal hierarquia hipotética, entretanto, tem implicações graves para a análise, pelo fato de estiupular que até mesmo o segmento plosivo menos marcado vai ser adquirido apenas posteriormente à fricativa mais marcada em termos de ponto. Por sua vez, sob a noção de restrições estringentes, deveríamos impor, de modo extrínsico, que $*[\{$ dorsal, labial, coronal $\} /$ stop $]_{\text {coda, }} *[\{\text { lab,coronal }\} / \text { stop }]_{\text {coda }}$ e $*[\{\text { coronal }\} / \text { stop }]_{\text {coda }}$ dominam as restrições em estringência $*[\{$ dors,lab, coronal $\} /$ fricative $]$ coda $*[\{\text { lab,coronal }\} / \text { fricative }]_{\text {coda }} \mathrm{e} *[\{\text { coronal }\} / \text { fricative }]_{\text {coda }}$. Tal tomada teórica significa impor um ranking fixo a uma hierarquia estringente, o que caracteriza um conflito teórico por apresentar uma hierarquia híbrida, em que é necessário recorrer a um ranqueamento fixo e externo para expressar uma relação hierárquica, concernente à sonoridade, que a restrições em estringência não conseguiram demonstrar.

Acreditamos ter ficado clara, assim, a necessidade de restrições advindas do alinhamento harmônico, tais como $*\{\text { stop }\}_{\text {coda }} \mathrm{e} *\{$ stop,fric $\}$ coda, que garantam as relações implicacionais entre segmentos de diferentes sonoridades em coda. Sendo necessárias essas restrições, o único jeito de obtermos uma formalização de restrições que faça referência a ponto de articulação em coda, sem implicar a existência de uma restrição que exerceria papel redundante à obtida do Alinhamento Harmônico, se dá através da Conjunção Local, uma vez que o operador ' $\&$ ' impedirá a formação de restrições tais como $\left[*\{\text { stop }\}_{\text {coda }} \& *\{\right.$ dors,lab,cor $\} /$ stop $]$ (coda) , de caráter redundante frente a $*\{\text { stop }\}_{\text {coda }}$, por exemplo.

\footnotetext{
${ }^{7}$ Precisamos reconhecer, ainda, que restrições como $*[\{\text { dors, lab, coronal }\} \text { / fricative }]_{\text {coda }}$ ferem o Princípio de Combinação entre Hierarquia e Estrutura proposto por De Lacy (2006), o que já confere a elas um caráter de inadequação formal, ao seguirmos tal princípio. Sob nossa proposta, somente restrições conjuntas se mostram capazes de expressar a oposição em coda sem violar tal princípio.
} 
Discutindo as Restriçốes de Marcaçấo Posicional: uma Proposta de Formalizaçāo da Diferença de Ponto de Articulaçấo em Coda

Finalmente, como último aspecto a ser ressaltado sobre o critério de economia, destacamos, ainda, a importância de formação de restrições conjuntas cujos componentes apresentem caráter estringente. Encontramos, nesse aspecto, uma vantagem de nossa proposta sobre à de formação de conjuntas tais como [Dorsal \& NoCoda] ou [Labial \& NoCoda $]^{8}$, sugerida por Zoll (1998). Consideremos, como ilustração, uma língua em que somente os segmentos coronais de um dado modo de articulação são possíveis em coda. Sob nossa proposta de restrições conjuntas com membros de caráter estringente, apenas uma restrição precisaria ser formada,uma vez que uma das restrições formadoras de tal conjunta faria menção à relação estringente $*\{$ dorsal,labial $\}$. Já sob a proposta de Zoll (1998), que não prevê a noção de membros da conjunta com caráter estringente, seriam necessárias duas restrições: uma que se oponha a labiais, e outra a dorsais, em coda?

Ao considerarmos o aspecto de adequação formal de nossa proposta, observamos, também, vantagens adicionais sobre restrições tais como $*[\{\text { labial }\} / \text { stop }]_{\text {coda }}$. Restrições desse tipo inegavelmente violam a Restrição de Combinação de Hierarquia e Estrutura proposta por De Lacy (2006), pelo fato de estarem associando um aspecto subsegmental a uma posição silábica.

\footnotetext{
${ }^{8}$ Julgamos importante mencionar que as restrições propostas por Zoll (1998) não fazem distinção em termos do grau de sonoridade do segmento em coda, de modo que não diferenciam fricativas e plosivas labiais em posição final de sílaba, por exemplo. Além disso, tais restrições pecam por não incluirem, em sua descrição estrutural, a caracterização de seu domínio. Para uma discussão acerca da importância da definição do domínio nas restrições conjuntas, aconselhamos a leitura de Bonilha (2005).

${ }^{9}$ Podemos mencionar, como exemplo, a classe das fricativas na posição da coda do português falado no dialeto gaúcho, em que fricativas labiais e dorsais não são permitidas. Ao seguirmos nossa formalização, apenas uma restrição conjunta $\left(\left[*\{\text { stop,fric }\}_{\text {coda }} \& *\{\text { dors,lab }\} / \text { fric }\right]_{(\text {coda })}\right)$ seria necessária para expressar a oposição a esses dois pontos. De fato, a formação de uma restrição tal como $\left[*\{\text { stop,fric }\}_{\text {coda }} \& *\{\text { dors }\} / \text { fric }\right]_{(\text {coda })}$ só se faria possível após a demoção da conjunta que faz menção ao ponto labial, ou seja, somente com a presença da fricativa labial em posição final na evidência positiva, pois antes disso tal restrição hipotética estaria assumindo papel redundante.
} 
Os membros constituintes das restrições conjuntas que apresentamos para lidar com as diferenças de ponto, por sua vez, seguem a premissa de obedecimento à Restrição de Combinação entre Hierarquia e Estrutura proposta por De Lacy, uma vez nenhuma das restrições componentes das restrições conjuntas atribuem uma oposição a ponto de articulação à posição prosódica de coda. Argumentos contrários ao obedecimento da restrição proposta por De Lacy (2006) por parte das conjuntas apresentadas em (06) e (07) poderiam ser apresentados ao considerarmos o fato de que o domínio de tais conjuntas é indiscutivelmente uma posição prosódica, ou seja, a coda silábica. De fato, a restrição $\left[^{*}\{\text { stop }\}_{\text {coda }} \&\right.$ $*\{$ dors $\} /$ stop $]_{\text {(coda) }}$ aqui proposta exerce o mesmo efeito, em termos de marca de violação, de $*\{\text { dorsal }\}_{\text {coda, }}$ que fere a condição proposta por De Lacy (2002, 2006): ambas são violadas sempre que uma plosiva dorsal ocorre em posição final de sílaba. Sob tal linha de raciocínio, as restrições conjuntas em estringência propostas por nosso trabalho poderiam vir a ser consideradas como desobedientes da Restrição de Combinação entre Hierarquia e Estrutura, visão essa da qual discordamos.

Argumentamos, aqui, que a Restrição de Combinação entre Hierarquia e Estrutura pode ser interpretada como um mecanismo de limitação que, ainda que exerça efeitos sobre a atribuição de conteúdo sobre uma posição prosódica, não exerce efeitos sobre o mecanismo de conjunção local. De fato, no que diz respeito à conjunção local, argumentamos que a "Restrição de Combinação entre Hierarquia e Estrutura" deve exercer efeitos sobre as restrições componentes da conjunta, mas não sobre a definição do domínio das restrições. Sob essa perspectiva, as restrições conjuntas propostas no presente trabalho não se mostram desobedientes à condição de De Lacy.

Argumentos que sustentem tal concepção se mostram bastante claros ao considerarmos os motivos que levaram De Lacy ao propor a Restrição de Combinação entre Hierarquia e Estrutura. De fato, tal postulado representa uma formalização da obediência ao Subset 
Discutindo as Restriçốes de Marcaçấo Posicional: uma Proposta de Formalizaçāo da Diferença de Ponto de Articulaçấo em Coda

Generalization (GOLDSMITH, 1990; BECKMAN, 1999), de acordo com o qual o inventário de coda é um subconjunto do de onset. Formalizações de restrições que, por exemplo, atribuam um categoria subprosódica à posição de onset, tal como $*[(\text { labial }\} / \text { stop }]_{(\text {onset })}$, estariam pondo em risco tal generalização, além de tornar o inventário de restrições menos econômico. De fato, ao considerarmos o fato de que uma restrição tal como $*[(\text { labial }\} / \text { stop }]_{\text {(onset) }}$ não apresenta, em termos formais, relação nenhuma com a posição de coda, nada impediria, em termos de tipologia fatorial, de serem concebidos sistemas em que o segmento labial /p/ é proibido em onset, mas não em coda. Frente a tal risco, De Lacy propõe a Restrição de Combinação entre Hierarquia e Estrutura, que, além de limitar consideravelmente a possibilidade de marcação em coda e, dessa forma, garantir maior economia e robustez em termos de tipologia fatorial, representa um artifício formal através do qual a Subset Generalization permanece obedecida.

Defendemos que nossa proposta não se mostra desafiadora da Restrição de Combinação entre Hierarquia e Estrutura pelo fato de garantir, também, que a Subset Generalization se mantenha respeitada, dado o fato de que as restrições conjuntas de marcação posicional fazem referência apenas à posição de coda, nunca à de onset.

Para demonstrarmos a afirmação feita acima, consideremos uma restrição tal como $\left[*\{\text { stop }\}_{\text {coda }} \& *\{\text { dors }\} / \text { stop }\right]_{(\text {coda })}$, formada para dar conta da produção de /k/ final. Argumentamos que uma restrição conjunta tal como $\left[*\{\text { stop }\}_{\text {coda }} \& *\{\text { dors }\} / \text { stop }\right]_{\text {(onset) }}$ nunca será formado pelo operador ' $\&$ ', pois essa sempre desempenharia um papel redundante: de fato, a restrição $*\{$ dors $\} /$ stop, que é uma das componentes da restrição conjunta, já desempenha o papel de se opor a plosivas dorsais em posição inicial de sílaba. Não é necessária, portanto, nenhuma restrição conjunta que se oponha a tal ponto em posição de onset. A noção de subconjunto é garantida pelo fato de que, para que a plosiva dorsal / $\mathrm{k} /$ seja produzida em coda, não somente $*\{$ dors $\} /$ stop 
e $*\{\text { stop }\}_{\text {coda }}$, mas também $\left[*\{\text { stop }\}_{\text {coda }} \& *\{\text { dors }\} / \text { stop }\right]_{\text {(onset) }}$, precisam encontrar-se em uma posição mais baixa no ranking. Retomamos, ainda, o fato de que em línguas em que a dorsal / k/ não é produzida em onset, a restrição conjunta também não será necessária; tal fato é garantido através da própria formalização de restrições que propomos, pois, se um dos componentes da conjunta nunca for demovido (no caso $*\{$ dors $\} /$ stop, que só é demovida a partir da evidência positiva com o segmento /k/ em posição inicial), o processo de Conjunção Local não ocorre, uma vez que a possível restrição conjunta estaria violando a premissa de redundância.

Assim, a formalização de restrições conjuntas estringentes garante, também, a obediência à Subset Generalization, uma vez que possibilita que segmentos em coda só sejam adquiridos após estarem presentes também em onset. Uma vez que nossa formalização de restrições conjuntas não desafia tal premissa, acreditamos que a condição proposta por De Lacy (2006) mantém-se preservada, atuando sobre cada uma das restrições individuais que compõem as restrições conjuntas. Nada mais precisa ser dito, de fato, em função de que os próprios princípios de formação das conjuntas já garante que a noção de subconjunto seja respeitada. Temos, portanto, uma proposta que se mostra adequada em termos de formalização de restrições, por não desobedecer ao Subset Generalization e, além disso, garantir uma análise mais econômica.

Finalmente, ressaltamos, também como um argumento favorável à noção de adequação formal da análise, o fato de que a noção de estringência acaba com a necessidade de uma estipulação extrínsica referente ao ranqueamento de restrições, o que se faria necessário ao considerarmos um ranking fixo. Para exemplificar, podemos pensar no processo de aquisição de L1. Uma grande gama de autores (DEMUTH 1995, LEVELT 1995, PATER \& PARADIS 1996, SMOLENSKY 1996, GNANADESIKAN 2004, LEVELT \& VAN DE VIJVER 2004, DAVIDSON et al. 2004) argumentam a favor de uma hierarquia 
Discutindo as Restriçốes de Marcaçấo Posicional: uma Proposta de Formalizaçāo da Diferença de Ponto de Articulaçấo em Coda

de restrições inicial em que as restrições de marcação dominam as de fidelidade $(\mathrm{M}>>\mathrm{F})$. Ao concebermos a existência de rankings fixos, tais como $*\{$ dorsal $\}>>$ labial $\}>>$ coronal $\}$, como poderemos organizar tais restrições de marcação, no estágio inicial de aquisição? Em termos do algoritmo de Aprendizagem Gradual (BOERSMA \& HAYES, 2001), deveríamos dizer que cada uma dessas restrições já apresenta um valor numérico distinto, mesmo no estágio inicial? $\mathrm{Na}$ verdade, a implementação computacional de tal algoritmo, através do software Praat (BOERSMA \& WEENINK, 2008), permite que estipulemos o número de rankings fixos com que a análise deverá obedecer, o que parece solucionar o problema. Entretanto, consideramos tal estipulação como de caráter extrínseco, uma vez que se caracteriza como uma determinação externa por parte do pesquisador, determinação essa que não pode ser resgatada através da noção de marcas de violação das restrições.

Sob nossa proposta, através de restrições de caráter estringente, nenhuma estipulação de ranking fixo é necessária: na implementação computacional do algoritmo, todas as restrições, no primeiro estágio de aquisição de L1, podem ser consideradas com os mesmos valores numéricos, sem que rankings fixos extrínsicos precisem ser estipulados. As relações hierárquicas entre as restrições são resgatadas pelas próprias marcas de violação incorridas por cada uma dessas restrições que formam conjuntos estringentes, de modo que tais relações hierárquicas se façam sentir a partir da própria descrição estrutural da restrição, sem nada mais ser necessário.

Problema semelhante pode ser encontrado, também, na formação de restrições conjuntas como [Dorsal \& NoCoda] ou [Labial \& NoCoda], conforme propostas por Zoll (1998). Considerando-se que tais restrições conjuntas não se encontram armazenadas em CON desde o início do processo de aquisição de L1, o mesmo problema pode ser encontrado, por exemplo, no momento em que a restrição referente ao ponto coronal, menos marcado, começa a ser demovida. Nesse momento, deverão 
ser formadas duas restrições conjuntas, uma referente ao ponto labial ([Labial \& NoCoda]) e uma ao ponto dorsal ([Dorsal \& NoCoda]). Um questionamento inevitável diz respeito a se um ranqueamento extrínsico entre essas duas restrições deve ser estipulado, uma vez que dorsais são mais marcadas do que labiais (PRINCE \& SMOLENSKY 1993/2004, DE LACY 2002, 2006). Vale retomar que, sob nossa proposta, a demoção de uma restrição tal como $*\{\text { stop }\}_{(\operatorname{coda} a}$ implicaria a formação de apenas uma restrição conjunta, $\left[*\{\text { stop }\}_{\text {coda }} \& *\{\text { dors,lab }\} / \text { stop }\right]_{\text {(coda) }}$ . Uma restrição tal como $\left[*\{\text { stop }\}_{\text {coda }} \& *\{\text { dors }\} / \text { stop }\right]_{(\text {coda })}$, de caráter mais específico, só seria formada a partir da demoção de tal restrição. Em outras palavras, a noção de estringência com que operamos não somente possibilita que as restrições referentes a ponto não necessitem apresentar um ranking fixo entre si, mas, também, um número menor de restrições conjuntas a serem formadas.

Em suma, apresentamos, na seção que aqui se encerra, aspectos vantajosos da teoria de restrições conjuntas em relação de estringência frente a restrições de marcação referentes à ponto de articulação em coda tais como $*(\text { coronal })_{\text {coda }}, *[$ (coronal $) /$ stop $]_{(\text {coda })}$ ou $*[$ (dorsal, labial, coronal)/stop $]_{(\text {coda })}$, encontradas na literatura. Tendo sido evidenciadas as vantagens tanto do ponto de vista econômico quanto do de adequação formal, é preciso, ainda, discutir o alcance e as limitações de nossa proposta. Nesse sentido, precisamos perguntar se nossa formalização se mostraria capaz de dar conta de quaisquer limitações a ponto de articulação em coda, além das verificadas no processo de aquisição de L2 aqui discutido. A esse respeito versará a seção que segue.

\subsection{Alcance da proposta}

Ainda que restrições conjuntas não necessariamente precisem se mostrar presentes em todas as línguas, uma vez que é o operador "\&", e não as restrições conjuntas dele resultantes, que apresenta um caráter universal, julgamos interessante discutir a aplicabilidade de nossa 
Discutindo as Restriçốes de Marcaçấo Posicional: uma Proposta de Formalizaçāo da Diferença de Ponto de Articulaçáo em Coda

proposta a outros casos de análise referentes a ponto de articulação em coda. Nesta seção, discutiremos a possibilidade de formação de restrições conjuntas estringentes referentes a ponto em casos que vão além do processo de aquisição de L2, que serviu como base para o desenvolvimento da proposta. Frente a essa tarefa, discutiremos, nesta seção, a aplicabilidade de formalização referente a codas com mais de um elemento, bem como a operação do operador " $\&$ " no próprio processo de aquisição de língua materna. Por fim, discutiremos a possibilidade de formação de tais restrições conjuntas nas diversas línguas do mundo.

Ao pensarmos na aplicabilidade da noção de restrições conjuntas de caráter estringente a contextos que vão além do de coda simples, defendemos que a proposta de formalização aqui apresentada se mostra capaz de dar conta, também, de codas complexas. Para exemplificação, citamos Alves (2008), em que restrições conjuntas são necessárias para diferenciar o processo de aquisição (L2) das sequências finais /pt/ e /kt/. Ao passo que a aquisição da sequência /pt/ implica apenas a demoção de $*\{\text { DIST } 0\}_{\text {coda }}$, que se opõe a plateaux de sonoridade em $\operatorname{coda}^{10}$, a aquisição de / kt/ exige não somente a demoção dessa, mas, também, da restrição conjunta $\left[*\{\text { DIST } 0\}_{\text {coda }} \& *\{\text { dors }\} / \text { stop }\right]_{(\text {coda })}$, o que comprova o caráter mais marcado dessa sequência, comprovado nos dados do autor. Ao observarmos as restrições componentes de tal restrição, vemos os mesmos princípios seguidos para a formação de restrições conjuntas estringentes referentes a codas simples: a conjunção de uma restrição referente à sonoridade com uma restrição referente a ponto em um modo de articulação específico (manner-specific constraint, cf. De Lacy, 2006). Defendemos, assim, que os mesmos princípios obedecidos para a formalização de restrições que se opõem a codas simples podem ser observados, também, na formação de restrições conjuntas que se opõem a codas complexas, de modo que possamos expandir o escopo de atuação da proposta aqui apresentada.

\footnotetext{
${ }^{10}$ Para maiores detalhes a respeito de tal restrição, aconselhamos a leitura de Alves (2008).
} 
Além de verificarmos a aplicabilidade da proposta em codas de mais de uma obstruinte, julgamos importante verificar se o mecanismo de formação de restrições conjuntas referentes a ponto pode, também, atuar na própria aquisição de língua-materna. Com base em Bonilha (2003, 2005), argumentamos que o operador ' $\&$ ' se encontra ativo desde a L1, de modo a formar restrições conjuntas que vão representar dificuldades para a criança, ao longo do processo de aquisição de primeira língua. Com o desenvolvimento da linguagem, tais restrições passam a ser demovidas; algumas dessas restrições, entretanto, continuam altamente ranqueadas, o que contribui para explicar as diferenças nos graus de marcação das línguas.

Acreditamos que esse seja o caso da proibição ao segmento [f] em coda, em nossa língua. De fato, ainda que fricativas coronais sejam permitidas, as labiais não o são, o que, à luz da nossa proposta, caracteriza-se como a ação de uma restrição conjunta referente a ponto de articulação, $\left[*\{\text { stop, fric }\}_{\text {coda }} \& *\{\text { dors,lab }\} / \text { fric }\right]_{(\text {coda })}{ }^{11}$. A formação de tal restrição conjunta se dá no próprio processo de L1: uma vez que o operador ' $\&$ ' trabalha sob o princípio da não-redundância, tal formação se dará a partir da demoção de *\{stop, fric $\}_{\text {coda }}$, ou seja, quando a criança for exposta à evidência positiva com a fricativa coronal, na L1. Tal restrição conjunta, no caso de nossa língua, nunca é demovida, uma vez que o segmento [f] é sempre proibido em coda; poderá vir a demovida, de fato, somente a partir de exemplares da fricativa labial na evidência positiva, o que ocorre na aquisição de L2. Defendemos, com base na restrição que se opõe a codas com fricativa labial, que o operador ' $\&$ ' se

\footnotetext{
${ }^{11}$ A restrição [*\{stop, fric $\}_{\text {coda }} \& *\{$ dors,lab $\} /$ fric $]_{\text {coda) }}$ foi proposta em Alves (2008), de modo a representar a proibição, no dialeto gaúcho, de qualquer fricativa em coda a não ser a coronal. Acreditamos que essa restrição se mostre ativa, inclusive, em dialetos do português brasileiro que apresentam fricativas dorsais em coda. Nesses dialetos, a oposição a $[\mathrm{f}]$ final seria garantida pela restrição conjunta em questão. A emergência de $[\mathrm{h}]$ seria possibilitada através da subespecificação de $/ \mathrm{R} /$, e de restrições mais altamente ranqueadas capazes de dar conta do mapeamento $/ \mathrm{R} / \rightarrow$ [h], restrições essas sobre as quais não nos concentraremos no presente trabalho.
} 
Discutindo as Restriçốes de Marcaçấo Posicional: uma Proposta de Formalizaçāo da Diferença de Ponto de Articulaçấo em Coda

mostra ativo, e segue os mesmos princípios, tanto na aquisição de L $1^{12}$ como de L2.

Uma vez que consideramos que a possibilidade de formação de restrições conjuntas estringentes referentes a ponto de articulação em coda se mostra disponível também no processo de aquisição de L1, nada nos impede de pensar na possibilidade de formação de tais restrições ao longo do processo de aquisição de diferentes línguas. Nesse sentido, por exemplo, poderíamos considerar que, ao longo do processo de aquisição do inglês ou do holandês como L1, as restrições [* $\{\text { stop }\}_{\text {coda }} \&$ $*\{$ dors,lab $\} /$ stop $]_{(\text {coda })}$ e $\left[*\{\text { stop }\}_{\text {coda }} \& *\{\text { dors }\} / \text { stop }\right]_{(\text {coda })}$ foram também formadas, de modo a caracterizarem as dificuldades iniciais das crianças falantes dessas duas línguas com os segmentos $[\mathrm{p}]$ e $[\mathrm{k}]$ em coda ${ }^{13}$. Uma vez que tal língua apresenta plosivas finais, tais restrições, entretanto, foram demovidas ao longo do processo de aquisição, de modo a apresentarem, no sistema adulto, um status hierárquico baixo. No caso da gramática adulta dessas línguas, as restrições em questão já se encontram com um valor baixo no ranking, uma vez que foram superadas pelas restrições de fidelidade. Seu papel efetivo foi desempenhado ao longo do processo de aquisição de L1, na dificuldade inicial de produção das plosivas finais, por parte das crianças.

\footnotetext{
${ }^{12}$ Acreditamos que o mesmo pode ter ocorrido, na aquisição da L1, com os outros membros, de caráter menos marcado, da escala de sonoridade. Dessa forma, é possível que no momento em que $*\{\text { stop, fric,nas }\}_{\text {coda }}$ tenha começado o seu processo de demoção, na aquisição do PB como L1, uma conjunta tal como ${ }^{*}\{\text { stop, fric,nas }\}_{\text {coda }} \&\{$ dors,lab $\} /$ nasal $]_{(\text {coda) }}$, que representaria oposição a nasais labiais e dorsais em coda, tenha sido formada. Uma vez que encontramos em nossa língua palavras como 'campo' e 'manco', tal restrição, na fala do adulto, já se encontra bastante baixa no ranking.

${ }^{13}$ Os dados de Fikkert \& Levelt (2006) confirmam que, na aquisição das plosivas em coda do holandês (L1), a plosiva dorsal é a última a ser adquirida, o que sugere ser pertinente a utilização de nossa proposta de formalização da oposição a /p/, /t/ e / k/ no processo de aquisição de outras línguas.
} 
As considerações acima feitas representam, ainda, hipóteses acerca do possível papel das restrições conjuntas em relação de estringência nas diversas línguas do mundo, sendo necessários maiores investigações sobre a questão. Julgamos como uma tarefa de pesquisa importante buscar evidências de que restrições conjuntas com o caráter aqui proposto podem ser formadas em diferentes línguas, para que possamos concluir que o princípio de formação de restrições conjuntas em estringência é de caráter universal. Tal tarefa abre caminhos, de fato, para uma vasta agenda de pesquisa.

\section{Conclusão}

Neste trabalho, apresentamos uma proposta alternativa de formalização de marcação posicional referente à coda silábica. Tal proposta tem por base a noção de formação de restrições conjuntas de caráter estringente, ao concebermos tal possibilidade de formação como disponível tanto ao longo do processo de aquisição de L1 como de L2. Argumentamos, ao longo do desenvolvimento da proposta, que a formalização aqui sugerida apresenta vantagens frente a rankings tais como $*[\{\text { dorsal }\} / \text { stop }]_{\text {coda }}>>*[\{\text { labial }\} / \text { stop }]_{\text {coda }}>>*[\{$ coronal $\} /$ stop $]$ coda ou $*[\{\text { dorsal }\} / \text { stop }]_{\text {coda }}, *[\{\text { dorsal,labial }\} / \text { stop }]_{\text {coda }} *[\{$ dorsal, labial, coronal $\} /$ stop $]_{\text {coda }}$, sobretudo sobre dois aspectos centrais: economia de análise e adequação formal.

É importante dizer, ainda, que a proposta aqui apresentada se mostra relevante para as discussões não somente acerca do processo de aquisição de linguagem, mas, também, para a investigação acerca do papel do mecanismo de conjunção local, pelo fato de sugerir princípios limitadores para a formação de restrições conjuntas. Nossa proposta demonstra que tal mecanismo se mostra capaz de representar a marcação posicional referente à coda, a partir de princípios claros e delineados acerca da formação de restrições. Concebemos que tal mecanismo deva 
Discutindo as Restriçốes de Marcaçấo Posicional: uma Proposta de Formalizaçāo da Diferença de Ponto de Articulaçáo em Coda

sempre operar sob a noção de Conjunção Local como último recurso (FUKAZAWA, 1999, 2001; FUKAZAWA \& MIGLIO, 1998), bem como reconhecemos a necessidade de princípios claros para a formação de restrições conjuntas. Acreditamos que, dessa maneira, poderemos ver o operador ' $\&$ ' como um mecanismo universal de formação de restrições, mecanismo esse que segue princípios referentes à limitação de sua atuação, sendo tal limitação fundamental.

Assim, com base na afirmação de McCarthy (2008) de que o quadro atual de pesquisas em OT tem como um de seus focos o desenvolvimento e o aperfeiçoamento do conjunto de restrições disponíveis em CON, esperamos que, com a proposta aqui apresentada, tenhamos conseguido contribuir não somente para um entendimento sobre o processo de aquisição de L1 e L2, mas, sobretudo, para uma reflexão acerca da formalização e da descrição estrutural das restrições de marcação utilizadas neste modelo teórico. Frente ao número de restrições de marcação redundantes que podemos encontrar na já expressiva quantitade de trabalhos desenvolvidos à luz do modelo, julgamos tal reflexão como de grande importância.

\section{Referências}

ALVES, Ubiratã Kickhöfel. A aquisição das sequências finais de obstruintes do inglês (L2) por falantes do Sul do Brasil: análise via Teoria da Otimidade. 337 f. Tese (Doutorado). Pontifícia Universidade Católica do Rio Grande do Sul, Porto Alegre, 2008.

BAPTISTA, Barbara O.; SILVA-FILHO, Jair L. A. The influence of voicing and sonority relationships on the production of English final consonants. In: BAPTISTA, Barbara O. WATKINS, Michael A. English with a Latin beat: Studies in Portuguese/Spanish-English Interphonology. John Benjamins, 2006. p. 73-90. 
BECKMAN, Jill. Positional Faithfulness. 270 f. Tese (Doutorado). University of Massachusetts, Amherst, 2002.

BOERSMA, Paul; HAYES, Bruce. Empirical tests of the Gradual Learning Algorithm. Linguistic Inquiry, n. 32, p. 45-86, 2001. ; WEENINK, David. PRAAT - Doing phonetics by computer. Disponível em: <http://www.fon.hum.uva.nl/praat/> Acesso em: 2008.

BONILHA, Giovana Ferreira Gonçalves. Conjoined Constraints and Phonological Acquisition. Journal of Portuguese Linguistics, v. 2, n.2, p. 7-30, 2003.

Aquisição fonológica do português brasileiro: uma abordagem conexionista da Teoria da Otimidade. 371 f. Tese (Doutorado). PUCRS, Porto Alegre, 2005.

CARDOSO, Walcir. The variable acquisition of English word-final stops by Brazilian Portuguese speakers. In: DEKIDTSPOTTER, Laurent et al. (eds.). Proceedings of the 7th Generative Approaches to Second Language Acquisition Conference (GASLA 2004). Somerville, MA: Cascadilla Proceedings Project, 2005.

DE LACY, Paul. The formal expression of markedness. Tese (Doutorado). University of Massachusetts, Amherst, 2002.

. Markedness: reduction and preservation in phonology. Cambridge University Press, 2006.

DAVIDSON, Lisa; JUSCZYK, Peter; SMOLENSKY, Paul. The initial and final states: theoretical implications and experimental explorations of Richness of the Base. In: KAGER, René; PATER, Joe; ZONNEVELD, Wim. Constraints in Phonological Acquisition. Cambridge University Press, 2004. p. 321-368. 
Discutindo as Restriçốes de Marcaçấo Posicional: uma Proposta de Formalizaçāo da Diferença de Ponto de Articulação em Coda

DEMUTH, Katherine. Markedness and the development of prosodic structure. NELS n. 25, p. 13-25, 1995.

FIKKERT, Paula; LEVELT, Clara C. How does place fall into place? The lexicon and emergent constraints in the developing phonological grammar. In: AVERY, P.; DRESHER, B. Elan \& RICE, K. Contrast in phonology: Perception and Acquisition. Berlin: Mounton, no prelo, p. 219-256.

FUKAZAWA, Haruka. Theoretical Implications of OCP effects on features in Optimality Theory. Tese (Doutorado). University of Maryland, College Park, 1999.

. Local Conjunction and Extending Sympathy Theory: OCP Effects in Yucatec Maya. In: LOMBARDI, Linda. Segmental Phonology in Optimality Theory: Constraints and Representations. Cambridge University Press, 2001, p. 231-260.

; MIGLIO, Viola. Restricting Conjuction to Constraint Families. Proceedings of Western Conference on Linguistics, v. 9, p. 102-117, 1998.

GNANADESIKAN, Amalia. Markedness and faithfulness constraints in child phonology. In: KAGER, René; PATER, Joe; ZONNEVELD, Wim. Constraints in Phonological Acquisition. Cambridge University Press, 2004, p. 73-108.

GOLDSMITH, John A. Autosegmental and Metrical Phonology. Blackwell, 1990.

ITÔ, Junko; MESTER, Armim. Markedness and Word Structure: OCP Effects in Japanese. Rutgers Optimality Archive, 255, 1998. Disponível em: <www.roa.rutgers.edu>. Acesso em: 18 jul. 2007. 
LEVELT, Clara C. Unfaithful kids: Place of Articulation patterns in early vocabularies. Colóquio apresentado na University of Maryland, 1995.

; Van de VIJVER, Ruben. Syllable types in cross-linguistic and developmental grammars. In: KAGER, René; PATER, Joe; ZONNEVELD, Wim. Constraints in Phonological Acquisition. Cambridge University Press, 2004. p. 204-218.

LOMBARDI, Linda. Why place and voice are different: constraintspecific alternations in Optimality Theory. In: LOMBARDI, L. (ed.). Segmental Phonology in Optimality Theory: Constraints and Representations, 2001. p. 13-45.

PRINCE, Alan. Paninian relations. Handout - University of Massachusetts, Amherst.1997a. Disponível em: <http://ling.rutgers. edu/gamma/talks/umass1997.pdf>. Acesso em: 18 jul. 2007.

. Stringency and anti-Paninian hierarchies. Unpublished manuscript. Ithaca, NY: Cornell University, 1997b. Disponível em: $<$ http://ling.rutgers.edu/gamma/talks/insthdt2.pdf $>$.

; SMOLENSKY, Paul. Optimality Theory: Constraint interaction in generative grammar. Manuscrito: Rutgers University and University of Colorado at Boulder, 1993. Versão revista: Blackwell, 2004.

KOERICH, Rosana Denise. Perception and Production of Vowel Epenthesis in Word-Final Single Consonant Codas. 261 f. Tese (Doutorado). Universidade Federal de Santa Catarina, Florianópolis, 2002.

McCARTHY, John. Doing OT. Blackwell, 2008. 
Discutindo as Restriçốes de Marcaçấo Posicional: uma Proposta de Formalizaçāo da Diferença de Ponto de Articulaçấo em Coda

PATER, Joe; PARADIS, Johanne. Truncation without templates in child phonology. In: STRINGFELLOW, A.; CAHANA-AMITAY, D.; HUGHES, E.; ZUKOWSKI, A. (eds.). Proceedings of the $20^{\text {th }}$ Annual Boston Universal Conference on Language Development. Somerville, Mass: Cascadilla Press. 1996, p. 540-551.

SILVEIRA, Rosane. The influence of pronunciation instruction on the perception and the production of English word-final consonants. 274 f. Tese (Doutorado). Universidade Federal de Santa Catarina, Florianópolis, 2004. . Investigating the role of orthography in the acquisition of L2 pronunciation: a case study. In: New Sounds 2007 - Fifth International Symposium on the Acquisition of Second Language Speech. Florianópolis, 2007.

SMOLENSKY, Paul. The Initial State and 'Richness of the Base' in Optimality Theory. Rutgers Optimality Archive, n. 118, 1996. Disponível em: < www.roa.rutgers.edu> . Acesso em: 18 jul. 2007.

ZOLL, Cheryl. Positional Asymmetries and Licensing. Rutgers Optimality Archive, n. 228, 1998. Disponível em: <www.roa.rutgers. $\underline{\mathrm{edu}}>$. 